\title{
Celebratio Mathematica: An Interview with Karen Uhlenbeck and Three New Volumes on Women Mathematicians
}

Sheila Newbery

Mathematical Sciences Publishers (msp . org) is pleased to announce the publication of three new volumes devoted to the careers of Karen Uhlenbeck, Joan Birman, and Dusa McDuff as part of its electronic archive of mathematicians of note, Celebratio Mathematica. The work was supported with funding from the Mathematical Sciences Research Institute (msri . org) and spearheads an intensive project now underway to develop the archive's holdings on the careers and accomplishments of women mathematicians. The support made it possible to undertake a number of special projects for these volumes, one of which we highlight here: a new interview with Karen Uhlenbeck by Allyn Jackson (the latter needing no introduction to readers of the Notices).

Interviews like this are especially valuable to students of mathematics for whom knowledge about the careers of other women scientists can be powerfully reinforcing. In publishing them, we aim to inspire student readers especially by showing them that there are diverse paths to a career in the sciences. What leads women to mathematics is perhaps not so different in essence from what makes men choose math, but the social and institutional realities of women's careers have been different enough from those of men to warrant thoughtful attention. This fact is certainly one of the subjects of the interview.

Sheila Newbery is the managing editor of Celebratio Mathematica (celebratio.org), an online archive of mathematicians of note published by Mathematical Sciences Publishers (msp.org). Her email address is shei1a@msp.org.

For permission to reprint this article, please contact: reprint -permission@ams.org.

DOI: https://dx.doi.org/10.1090/noti 1807
The story of how Uhlenbeck became a mathematician is traced with a nuance that builds on Claudia Henrion's earlier account in Women in Mathematics: The Addition of Difference. ${ }^{1}$ One detail that emerges clearly is the significance of Uhlenbeck's mother's social circle. Carolyn Keskulla was a painter, and Uhlenbeck remembers vividly as a girl that her mother's painter friends and artistic interests brought her into contact with "a lot of people who did not live normal, middle-class lives." The liveliness and eccentricity of this crowd made a lasting impression. Moreover, like her own mother (Uhlenbeck's grandmother), Carolyn was a strong, intelligent, active woman, so the value for intellectual endeavor and the uses of the imagination were early and firmly established in the family circle.

Jackson also explores the relevance of talent, and frames it instructively in the context of opportunities afforded by education: high school, first, and then a high-quality public university education. While Uhlenbeck's family background emphasized intellectual attainment, her high school gave her no specific encouragement vis-à-vis mathematics. The first seeds of mathematical inspiration were sown at university. The following excerpt from Jackson's article (see pull quote, facing page) highlights that revelatory moment, which occurred during Uhlenbeck's time as an undergraduate.

\footnotetext{
${ }_{1}^{1}$ Bloomington: Indiana University Press, 1997, pp. 25-46.
} 


\section{HISTORY}

When I first read these words (while preparing the manuscript for publication), I was struck by them: for many women of Uhlenbeck's generation, the question of what one was or wasn't allowed to do was never too far from lived experience. Her word choice seemed telling. Yet the emotional impact of the episode is gloriously positive: it is one of deep intellectual excitement.

Although Uhlenbeck faced certain obstacles, such as the impossibility even as a gifted student of applying to or attending either of the nearby all-male colleges (Princeton and Rutgers), she nevertheless had access to a superb university education at the University of Michigan, and that was how she gained her first significant exposure to higher mathematics. In the post-Sputnik era of the 60s, moreover, federal agencies were issuing a clarion call to talented students, encouraging them to pursue a career in math and science after college. That posture had clear benefits for Uhlenbeck. As she puts it, "They were encouraging everybody, and women counted."

Jackson touches on the importance of mathematical collaboration-in Uhlenbeck's case, with such colleagues as Jonathan Sacks, Lesley and Robert Sibner, S.-T. Yau, Richard Schoen, and Chuu-Lian Terng. The separate, detailed accounts here of Uhlenbeck's friendships with Yau and Lesley Sibner, in particular, vividly underscore the unpredictable swerves of social and intellectual opportunity that make up a career.

Jackson's keen sense of timing is one of her gifts as an interviewer, yet equally important is her ability to layer questions that illuminate the penumbra of intuition and wonder that motivate mathematical inquiry in the first place. So a question about mathematical "tastes" ("What kinds of mathematical problems appeal to you?") leads to a fascinating exchange about what Uhlenbeck refers to as one of the mysteries of mathematics: "[W]hy KdV comes up all over the place, in all sorts of geometric and physical problems."

In addition to Jackson's in-depth interview, we want to call readers' attention to several other unique contributions to these three new volumes: - Cliff Taubes on "Karen Uhlenbeck's contributions to gauge theoretic analysis";

- Leonid Polterovich and Felix Schlenk's article on Dusa McDuff's contributions to "Symplectic embedding problems";

- Bill Menasco's essay "My work with Joan Birman";

- Dan Margalit and Rebecca R. Winarski's overview of Joan Birman and Hugh Hilden's collaboration in "The Birman-Hilden theory."

Mathematical Sciences Publishers will continue to build its archive: soon to be published are volumes on the careers of Mary Ellen Rudin and Cathleen Morawetz. We welcome suggestions from the mathematical community for future volumes on women mathematicians, and we are grateful to MSRI for its support in making our work available in perpetuity to a broad readership.

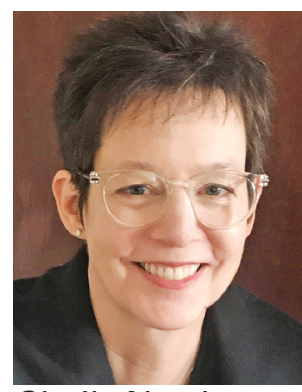

Sheila Newbery

Credits

Author photo is courtesy of Sheila Newbery. 